\title{
Retention of crowns cemented on implant abutments with temporary cements
}

\author{
Yuko NAGASAWA, Yasushi HIBINO and Hiroshi NAKAJIMA \\ Division of Dental Biomaterials Science, Department of Restorative and Biomaterials Sciences, Meikai University School of Dentistry, 1-1, Keyakidai, \\ Sakado, Saitama 350-0283, Japan \\ Corresponding author, Yuko NAGASAWA; E-mail: nagasawa@dent.meikai.ac.jp
}

\begin{abstract}
This study was to examine the retentive force of crowns to implant abutments with commercial temporary cements. Six different temporary cements were investigated. Cast crowns were cemented to the abutments using each cement and their retentive forces to abutments were determined 7 or 28 days after cementing $(n=10)$. The retentive force of the cements to abutments varied widely among the products [27-109 N (7-day), 18-80 N (28-days)]. The retentive force of all the cements was not reduced as the time elapsed, except for two products tested. The polycarboxylate cements and paste-mixing type eugenol-free cements revealed comparable retentive force after 28 days of storage. The powder-liquid type cements showed a positive correlation $(p<0.05)$ between the retentive force and the shear strength, while a negative correlation $(p<0.05)$ was obtained for paste-mixing type cement between the retentive force and compressive strength. Mechanical strength of temporary cements could not be a prominent predicting factor for retention of the crowns on the abutments.
\end{abstract}

Keywords: Dental cements, Dental implants, Retention, Temporary cements

\section{INTRODUCTION}

The dental implant prosthesis became a promising choice for dental restorations in the past decade. Several clinical studies ${ }^{1-3)}$ reported that fixed partial dentures on natural teeth had a mean life span of 5 to 13 years, while implant-supported fixed prostheses demonstrated a survival rate greater than $90 \%$ 4,5) at 10 to 15 years. These findings suggest that prosthetic treatments using dental implants are comparable to traditional prosthetic procedures in carefully selected clinical cases.

Although many types of dental implant systems are currently on the market, the basic components of dental implant prostheses consist of the implant abutment and the superstructure, i.e., the crown, which directly contributes to the occlusion. For the implant prosthesis to function correctly in the oral cavity, the implant abutment should be firmly fixed to the crown prosthesis during service. The two methods of fixing the crown prosthesis to the abutment involve screwing or cementing procedures ${ }^{6}$. The cement-retained implant prosthesis is cemented using procedures similar to those employed for natural teeth. There are several advantages of the cement-retained type compared to the screw-retained type. Few esthetic problems are expected for the cement-retained system because there is no screw hole on the prosthesis ${ }^{7-11)}$. The fracture of ceramic crowns or metal-ceramic crowns on the abutments or of the implant components was reported to be reduced in the cement-retained types ${ }^{7,12,13)}$. In addition, it was found that the space between the abutment and prosthesis in the screw-retained implants created an area where saliva and beverages could penetrate, acting as a source

Color figures can be viewed in the online issue, which is available at J-STAGE.

Received Apr 1, 2014: Accepted Aug 7, 2014

doi:10.4012/dmj.2014-100 JOI JST.JSTAGE/dmj/2014-100 of unpleasant odor and increasing the risk of corrosion of the abutment surfaces. On the other hand, the use of cement-retained implants eliminated these unclean spaces due to a layer of cement that prevented bacterial and oral fluid penetration between the implant and the abutment ${ }^{14)}$.

The cement used for a cement-retained implant needs to provide sufficient retention of the superstructure to the abutment and also to allow for retrieval of the superstructure from the abutment if necessary. In order to satisfy these requirements, temporary cements can be favorably used for this type of implant prosthesis ${ }^{8.11,15,16)}$. However, the optimum retentive force to an implant prosthesis is not clearly understood. Several investigations have reported on the retentive force of temporary cements ${ }^{8-11,15-20)}$, with the results showing that their retentive force ranged between 16 and $467 \mathrm{~N}^{8-11,19,20)}$. In a majority of these previous studies, the retentive force values were examined at 24 $\mathrm{h}$ after seating the crowns. There was no information on the retentive force of temporary cement at 7 days or more after seating. And little information is available on the relationships between the retentive forces of crown prostheses cemented to implant abutments with temporary cements and the mechanical properties of the cements.

The purposes of this laboratory study were to examine: (1) the retentive force of crowns retained on implant abutments with different types of temporary cements at 7 days after seating; (2) the effect of elapsed time in retentive force of the cements up to 28 days; and (3) the relationships between the retentive forces and the mechanical strengths (compressive strength and shear strength) of the cements found in our previous studies $^{21,22)}$. The hypotheses tested in this study are 
that the retentive forces of crown to implant abutment by temporary cements depend on the types of cements and the elapsed time after seating and that the retentive forces of crown to the implant abutment correlate with the mechanical strengths of the cements.

\section{MATERIALS AND METHODS}

\section{Materials}

Six different commercially available temporary cements were used: HY-Bond Temporary cement Soft (A, polycarboxylate cement; Shofu, Kyoto, Japan); HY-Bond Temporary cement (Hard) (B, polycarboxylate cement; Shofu, Kyoto, Japan); Freegenol temporary pack (C, paste mix-type without eugenol; GC, Tokyo, Japan); Temp Bond NE (D, paste mix-type without eugenol; Kerr, Orange, CA, USA); Temp Bond (E, paste mix-type with eugenol; Kerr, Orange, CA, USA) and Eugenol cement (F, zinc oxide-eugenol cement; GC, Tokyo, Japan) (Table 1).

\section{Retentive force measurement}

Truncated cone-shaped implant abutments (Easy Abutment, $5 \mathrm{~mm}$ cervical diameter and $5 \mathrm{~mm}$ high, 10-degree tapered, Nobel Biocare, Tokyo, Japan) were used in this study (Fig. 1). Cast crowns (copings) that fit the abutments were fabricated according to the following procedures. Preformed plastic copings specially made by the implant manufacturer $(5 \mathrm{~mm}$ inside diameter, $5 \mathrm{~mm}$ high) were invested in a phosphate-bonded casting investment (Velvety Superquick, Shofu, Kyoto, Japan). After burning out the molds according to the manufacturer's instructions, gold alloy for ceramic-metal restorations (TPW, Tokuriki Honten, Tokyo, Japan) was cast into the mold in an argon gas atmosphere using a pressure-casting machine (Argoncaster, Shofu, Kyoto, Japan) to fabricate the cast crowns. After casting, the crowns were removed from the mold and cleaned using ordinary laboratory procedures.

The thickness of the cement space between the abutment and cast crown was adjusted and confirmed

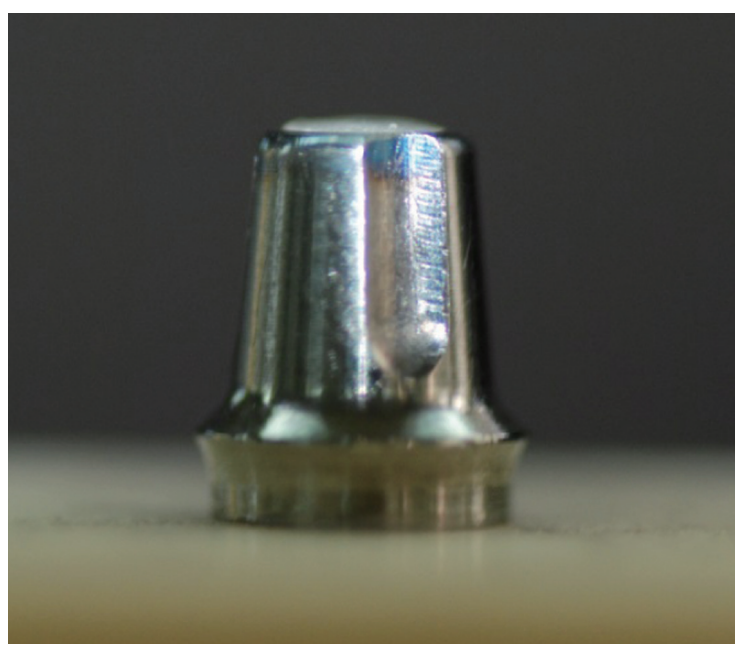

Fig. 1 Implant abutment used in this study. (There are three prefabricated grooves on the axial wall.)

Table 1 Temporary cements examined in this study

\begin{tabular}{|c|c|c|c|c|}
\hline Material & Composition & Lot No. & $\mathrm{P} / \mathrm{L}$ ratio & Code \\
\hline $\begin{array}{l}\text { HY-Bond Temporary } \\
\text { Cement Soft } \\
\text { (Shofu, Japan) }\end{array}$ & $\begin{array}{l}\text { Powder: } \mathrm{ZnO}, \mathrm{SiO}_{2}, \mathrm{MgO}, \mathrm{HY} \text { agent, other } \\
\text { Liquid: Poly (acrylic acid-tricarboxylic acid) } \\
\text { sodium salt, Water, other }\end{array}$ & $\begin{array}{l}\text { P: } 040418 \\
\text { L: } 040456\end{array}$ & $2.2 \mathrm{~g} / 1.0 \mathrm{g*}$ & $\mathrm{A}$ \\
\hline $\begin{array}{l}\text { HY-Bond Temporary } \\
\text { Cement (Hard) } \\
\text { (Shofu, Japan) }\end{array}$ & $\begin{array}{c}\text { Powder: } \mathrm{ZnO}, \mathrm{SiO}_{2}, \mathrm{MgO}, \mathrm{HY} \text { agent, other } \\
\text { Liquid: Poly (acrylic acid-tricarboxylic acid) } \\
\text { sodium salt, Water }\end{array}$ & $\begin{array}{l}\text { P: } 040447 \\
\text { L: } 050432\end{array}$ & $1.6 \mathrm{~g} / 1.0 \mathrm{~g} *$ & $\mathrm{~B}$ \\
\hline $\begin{array}{l}\text { Freegenol temporary pack } \\
\text { (GC, Japan) }\end{array}$ & $\begin{array}{c}\text { Base: } \mathrm{ZnO} \text {, Vegetable oil, Petrolatum } \\
\text { Accelerator: Oleic acid }\end{array}$ & 0406161 & \# & $\mathrm{C}$ \\
\hline $\begin{array}{l}\text { Temp Bond NE } \\
\text { (Kerr, USA) }\end{array}$ & $\begin{array}{l}\text { Base: Mineral oil, } \mathrm{ZnO} \text {, Cornstach } \\
\text { Accelerator: Ortho-Ethoxybenzoic acid, } \\
\text { Carnauba wax, Octanic acid }\end{array}$ & 3-1329 & \# & $\mathrm{D}$ \\
\hline $\begin{array}{l}\text { Temp Bond } \\
\text { (Kerr, USA) }\end{array}$ & $\begin{array}{l}\text { Base: Mineral oil, ZnO, Cornstach } \\
\text { Accelerator: 4-Allyl-2-Methoxyphenol (Eugenol, } \\
\text { Oil of cloves), Carnauba wax, Zinc acetate }\end{array}$ & $3-1307$ & \# & $\mathrm{E}$ \\
\hline $\begin{array}{l}\text { Eugenol Cement } \\
\text { (GC, Japan) }\end{array}$ & $\begin{array}{c}\text { Powder: } \mathrm{ZnO} \text {, Rosin, Other } \\
\text { Liquid: Eugenol }\end{array}$ & $\begin{array}{l}\text { P: } 0405261 \\
\text { L: } 0405261\end{array}$ & $1.0 \mathrm{~g} / 0.35 \mathrm{~mL}^{*}$ & $\mathrm{~F}$ \\
\hline
\end{tabular}

* manufacturer's recommended mixing ratio

\# equal lengths of base and accelerator pastes 
using a silicone rubber fit-indicating material (Fit Checker II, GC, Tokyo, Japan) as follows. After the base and catalyst pastes of the fit-indicating material were mixed according to the manufactures' instructions, the mixture was interposed between abutment and crown and the crown was pressed down toward the long axis of abutment by finger pressure until the indicating material set. The thickness of fit-indicating material corresponding to the axial surface of the abutment, excepting the grooves which were prefabricated by the manufacturer, was measured using a micrometer (MDC25MJ, Mitutoyo, Kanagawa, Japan). Until the indicating material thickness reached within the range of $50 \pm 10$ $\mu \mathrm{m}$, the inner surfaces of crown were carefully abraded using dental laboratory abrading burs and sandblasting. In order to provide the consistent surface roughness, the inner surfaces of crown were finished using glass beads blasting (50 $\mu \mathrm{m}$ glass beads, Shofu, Kyoto, Japan) and then the cement spaces were confirmed again to be within the range of $50 \pm 10 \mu \mathrm{m}$ using the fit-indicating material.

The implant abutment was embedded perpendicularly with a self-curing acrylic resin block (Provinice, Shofu, Kyoto, Japan) to allow the abutment portion to protrude from the resin surface. The open screw access hole in the center of the top surface of the abutment was filled with the silicone rubber fitindicating material to create a flat top surface on the abutment. Before cementing, both the inner surfaces of crowns and the abutment surfaces were wiped carefully using clean soft cloth with $99.5 \%$ ethanol for $30 \mathrm{~s}$ and dried with clean compressed canned air.

After each cement was mixed according the procedures recommended by the manufacturer, the cast crown was cemented on the abutment using each cement. The crown on the abutment was held by finger pressure (approximately $2 \mathrm{kgf}$ ) for $10 \mathrm{~min}$. Then, the excess cement mass at the margins was carefully removed by dental explorer. Thirteen minutes after the start of cement mixing, the specimens were placed in a container maintained at $37 \pm 2^{\circ} \mathrm{C}$ and $95 \pm 5 \%$ relative humidity and stored up to 28 days.

Seven or 28 days after cementation, the retentive force of the crown to the abutment was determined using a jig (Fig. 2) in a universal testing machine (4302, Instron, Buckinghamshire, UK) at a crosshead speed of $1.0 \mathrm{~mm} / \mathrm{min}$ at room temperature $\left(23 \pm 2^{\circ} \mathrm{C}\right)$. The maximum force required to remove the cast crown from the abutment was recorded as the retentive force. Ten specimens were fabricated and tested for each cement and each storage period. The results were statistically compared using a two-way ANOVA followed by Scheffe's test at $\alpha=0.05$. The significant level was set at $p=0.05$.

\section{Examination of the failure mode in the specimens after} retentive force measurement

To obtain information on the failure behavior of the cements, the residual cement mass remaining on either the surfaces of the crown or the abutment was examined after the retentive force measurement. After

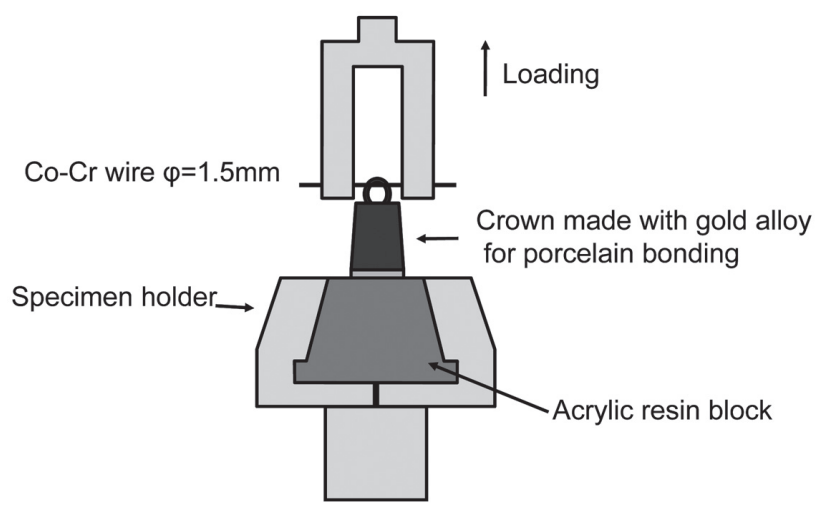

Fig. 2 Diagram showing retentive force measurements.

the retention force tests, the surfaces of abutment and the inner surfaces of crowns were examined using the stereomicroscope at $5 \times$ and the areas of remaining cement mass on the surfaces were estimated. The failure modes of de-bonded area were determined based on the estimated area of remaining cement mass on the specimen surfaces. The failure modes in the present study were classified into three types according to the previous study ${ }^{23}$ as follows: (1) The specimen that the residual cement mass remained on approximately $75 \%$ or more of the area of the inner surface of the crown is classified as "Residual cement mass on the crown"; (2) The specimen that the residual cement mass remained approximately $75 \%$ or more of the area of the axial surface of the abutment is classified as "Residual cement mass on the abutment"; and (3) if the specimen that the residual cement mass remained on an area less than approximately $75 \%$ of the surfaces of both the crown and the abutment, the specimen was classified as "Residual cement mass on the crown and abutment".

The estimation of the area of residual cement mass on the surfaces was replicated twice for each specimen and no inconsistent result was obtained between the first and the second estimations.

The results of failure mode examination were analyzed using chi-square tests with the significance level at $p=0.05$.

\section{Relationships between mechanical strength and retentive force}

In order to explore the relationships between the retention behavior of crowns to abutment and the mechanical properties of cements used, the correlation was examined between the retentive forces measured in the present study and the compressive and shear strengths of the cements reported in our previous studies ${ }^{21,22)}$ in which the cements identical to those tested in the present study were investigated (Table 3). The correlation coefficients were statistically compared using a Pearson product-moment correlation coefficient at $\alpha=0.05$ and the significance level was set at $p=0.05$. 


\section{RESULTS}

Retentive force of the temporary cements to the abutment The measured retentive force $(\mathrm{N}$, mean $\pm \mathrm{SD})$ of the cements tested to the abutment is shown in Fig. 3. The summary of statistical analysis is shown in Table 4. Two-way ANOVA indicated significant differences in the retentive force among the cements tested ( $F=40.999$, $p<0.0001$ ). Significant effect of storage time period was found in the retentive forces of the cement $(F=17.602$, $p<0.0001)$. Seven days after the start of storage in a moist atmosphere, cement $\mathrm{B}$, which was one of the polycarboxylate cements, had the greatest retentive

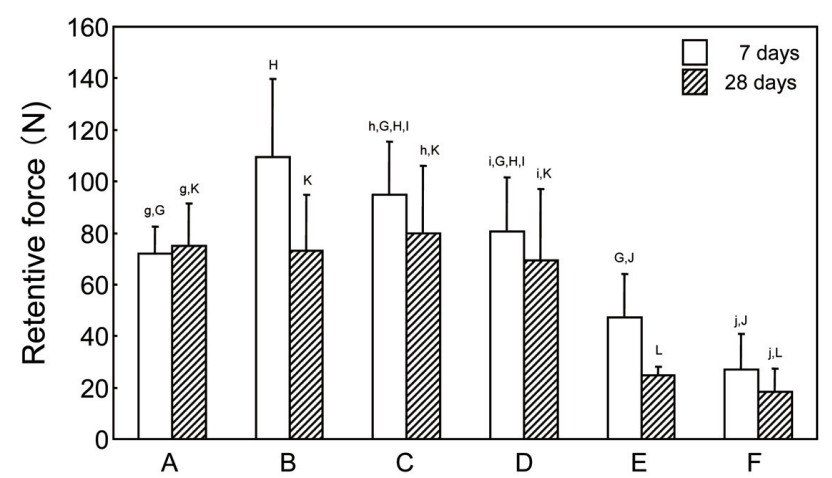

Fig. 3 Retentive force values for temporary cements at 7 and 28 days.

Same lower-case letters in each cement indicate no statistical differences $(p>0.05)$. Same upper-case letters at the same storage period indicate no statistical differences $(p>0.05)$. force $(109 \pm 30 \mathrm{~N})$, and zinc oxide eugenol cement $\mathrm{F}$ had the lowest retentive force $(27 \pm 14 \mathrm{~N})$ among the cements tested $(p<0.05)$. No significant differences in the retentive force were found at 7 days among cements $\mathrm{A}$ $(72 \pm 10 \mathrm{~N}), \mathrm{C}(95 \pm 21 \mathrm{~N}), \mathrm{D}(80 \pm 21 \mathrm{~N})$ and $\mathrm{E}(47 \pm 17 \mathrm{~N})$ $(p>0.05)$. The retentive force for cement $\mathrm{A}$ at 7 days showed lower values than those of cement B $(p<0.05)$. There were no significant differences in the retentive force values at 7 days between $\mathrm{E}$ and $\mathrm{F}(p>0.05)$. Cements $\mathrm{E}$ and $\mathrm{F}$ had significantly lower retentive force than the cements B, C and D $(p<0.05)$.

Twenty-eight days after the start of the storage, cements A, B, C and D revealed significantly greater retentive forces compared to the other cements $(p<0.05)$ but there were no statistical differences in the retentive force values among cements A, B, C and D ( $p>0.05)$. The retentive force measured for cement $\mathrm{E}$ did not statistically differ from that for cement $\mathrm{F}(p>0.05)$. Cements A, C, D and F did not significantly decrease in retentive force from seven to 28 days after the start of the storage period ( $p>0.05)$; however, the retentive force of the other cements was significantly reduced after 28 days' storage $(p<0.05)$.

Examination of the failure mode in specimens after retention measurement

Table 2 summarizes the failure mode of the specimens after retentive force testing. Figure 4 shows representative failure appearance of the specimen classified residual cement mass on the crown.

Seven days after the start of storage, the majority of the residual cement mass adhered on the inner surface of the crowns in the specimens cemented with cements A, D, E and F. On five out of ten specimens cemented with $\mathrm{B}$ or $\mathrm{C}$, the majority of the cement mass

Table 2 Summary of residual cement mass observed on the implant abutment surface and the inner surface of crown

\begin{tabular}{|c|c|c|c|c|}
\hline \multirow{2}{*}{ Cement } & & \multicolumn{3}{|c|}{ Residual cement mass on: } \\
\hline & & Crown & Abutment & Crown and abutment \\
\hline \multirow{2}{*}{ A } & 7 days ${ }^{\mathrm{gGM}}$ & 9 & 0 & 1 \\
\hline & 28 days $^{\mathrm{g}}$ & 4 & 2 & 4 \\
\hline \multirow{2}{*}{ B } & 7 days $\mathrm{GH}$ & 5 & 5 & 0 \\
\hline & 28 days ${ }^{\mathrm{MN}}$ & 0 & 7 & 3 \\
\hline \multirow{2}{*}{$\mathrm{C}$} & 7 days ${ }^{\text {hHJ }}$ & 4 & 5 & 1 \\
\hline & 28 days ${ }^{\mathrm{hMNP}}$ & 2 & 5 & 3 \\
\hline \multirow{2}{*}{$\mathrm{D}$} & 7 days jGK & 10 & 0 & 0 \\
\hline & 28 days ${ }^{j Q}$ & 9 & 0 & 1 \\
\hline \multirow{2}{*}{$\mathrm{E}$} & 7 days ${ }^{\mathrm{kGKL}}$ & 10 & 0 & 0 \\
\hline & 28 days ${ }^{\mathrm{kMPQR}}$ & 7 & 1 & 2 \\
\hline \multirow{2}{*}{$\mathrm{F}$} & 7 days ${ }^{m G H J K L}$ & 8 & 0 & 2 \\
\hline & 28 days $^{\mathrm{mQR}}$ & 9 & 0 & 1 \\
\hline
\end{tabular}

The numbers in the table represent the observed numbers of specimens.

Same lower-case letters in each cement indicate no statistical differences $(p>0.05)$.

Same upper-case letters at the same storage period indicate no statistical differences $(p>0.05)$. 
remained on the abutment surface. Cement $\mathrm{C}$ showed significant difference in failure mode from cements A, $\mathrm{D}$ and $\mathrm{E}(p<0.05)$. Failure mode found for cement B was significantly different from those of cements D and E $(p<0.05)$.

Twenty-eight days after the start of storage, the number of specimens with a residual cement mass adhering to the crown surface decreased for cements A,
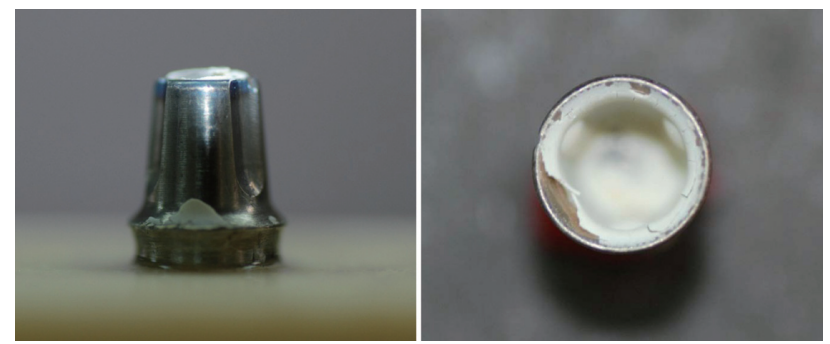

Fig. 4 Residual cement mass on abutment and crown. Abutment axial surface, left and the inner surface of crown, right (Cement A specimen, 7 days, specimen classified as failure mode Crown)
$\mathrm{B}$ and $\mathrm{C}$, while the number of specimens with the cement mass remaining on both the crown and the abutment surfaces increased after 28 days. Cements A, B and C exhibited significant differences in the failure modes after 28 days as compared to cement D $(p<0.05)$. Failure mode for cement B after 28 days significantly differed from those of cements D, E and F $(p<0.05)$. Cement C showed significant different failure mode from cement $\mathrm{F}$ after 28 days $(p<0.05)$.

Significant change in failure mode was observed only for cement B from 7 days to 28 days of storage $(p<0.05)$ but there were no significant changes in failure modes from 7 to 28 days for all the other cements $(p>0.05)$.

\section{Relationships between mechanical strength and retentive} force

The compressive and shear strengths of the cements which are identical products to those used in the present study are summarized in Tables 3 and 4. These data are cited from our previous published studies ${ }^{21,22)}$. The shear strengths were determined using the shear punch $\operatorname{method}^{24)}$.

Figures 5 (a) and 5 (b) plot the mean values of retentive force against the mean values of mechanical

Table 3 Mean compressive strength values (MPa) of temporary cement ${ }^{22)}$

\begin{tabular}{ccc}
\hline Cement & 7 days & 28 days \\
\hline A & $12.9(0.5)^{\mathrm{G}}$ & $15.1(0.8)^{\mathrm{L}}$ \\
B & $33.9(6.2)$ & $41.5(3.9)$ \\
C & $7.2(0.4)^{\mathrm{H}}$ & $9.8(0.6)^{\mathrm{M}}$ \\
D & $11.3(0.8)^{\mathrm{gGHJ}}$ & $10.1(2.1)^{\mathrm{gMN}}$ \\
E & $15.2(0.9)^{\mathrm{hGJK}}$ & $15.7(1.0)^{\mathrm{hLP}}$ \\
F & $11.2(1.1)^{\mathrm{jGHJK}^{\mathrm{h}}}$ & $12.0(1.5)^{\mathrm{jLMNP}}$ \\
\hline
\end{tabular}

Values in parenthesis represent standard deviation of means.

Same lower-case letters in each cement indicate no statistical differences between 7 and 28 days $(p>0.05)$.

Same upper-case letters at the same storage period indicate no statistical differences $(p>0.05)$.

Table 4 Mean shear strength values $(\mathrm{MPa})$ of temporary cements ${ }^{21}$

\begin{tabular}{clc}
\hline Cement & 7 days & 28 days \\
\hline A & $3.9(0.7)$ & $3.6(0.8)^{\mathrm{K}}$ \\
B & $5.6(0.8)$ & $5.5(0.8)$ \\
C & $2.7(0.2)^{\mathrm{G}}$ & $2.6(0.3)^{\mathrm{L}}$ \\
D & $2.2(0.2)^{\mathrm{GH}}$ & $2.3(0.6)^{\mathrm{LM}}$ \\
E & $2.6(0.3)^{\mathrm{GHJ}}$ & $2.3(0.2)^{\mathrm{LMN}}$ \\
F & $2.3(0.5)^{\mathrm{GHJ}}$ & $2.8(0.3)^{\mathrm{KLMN}}$ \\
\hline
\end{tabular}

Values in parenthesis represent standard deviation of means.

No statistical significant differences in shear strengths were found between 7 and 28 days for all the temporary cements $(p>0.05)$.

Same upper-case letters at the same storage period indicate no statistical differences $(p>0.05)$. 
strengths (compressive strength or shear strength) for all the cements examined. There were no significant correlations between mechanical strengths and retentive force values $[r=0.279(p=0.3802)$ for compressive strength
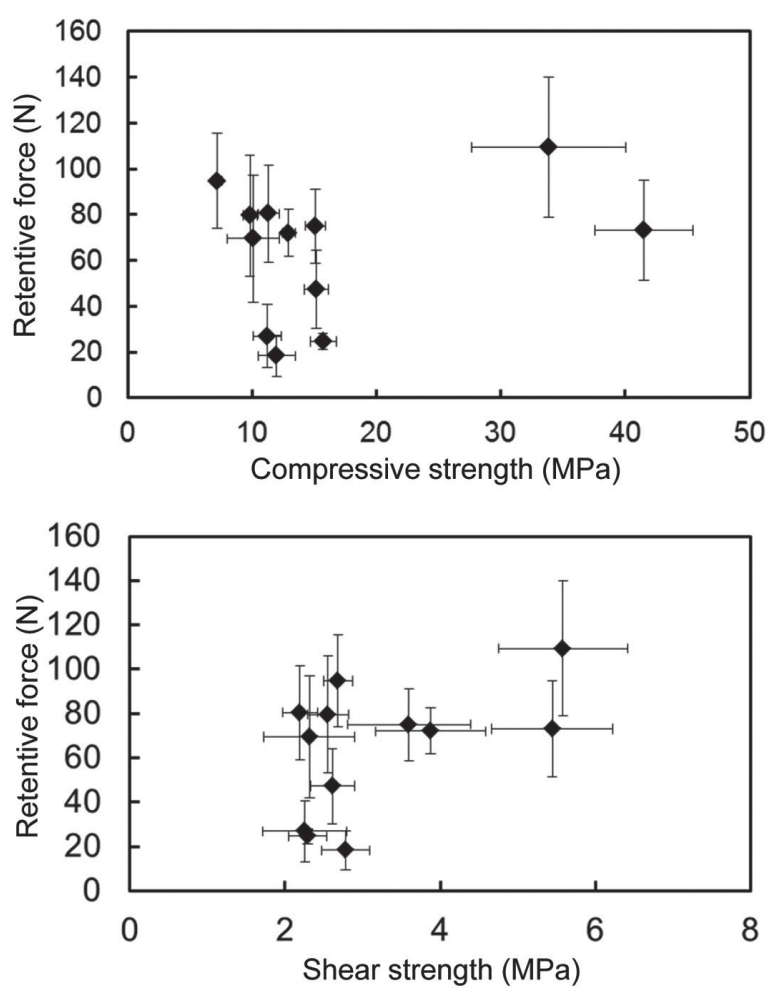

Fig. 5 Relationships between mechanical strengths and retentive force values of temporary cements used in this study.

Bars with symbol indicate one standard deviation. Symbols represent 7 -day and 28-day values, (a) Relationships between compressive strength and retentive force values. (b) Relationships between shear strength and retentive force values. and $r=0.499(p=0.0986)$ for shear strength].

Relationships between the retentive forces and the compressive strengths of the powder-liquid type cements (cements A, B and F) or those of the paste-mixing type cements (cements C, D and E) are shown in Figs. 6 (a) and 7 (a), respectively. Although the cements with greater compressive strengths tended to have greater retentive force for the powder-liquid type cements, there were statistically no significant correlation among them ( $r=0.634, p=0.1760$, Fig. 6 (a)). For the paste-mixing type cements, a significant negative correlation $(r=-0.936$, $p=0.0061$ ) was found between the compressive strength and the retentive force (Fig. 7 (a)).

Figures 6 (b) and 7 (b) show relationships between the retentive forces and the shear strengths of the powder-liquid cements (cements A, B and F) or those of the paste-mixing type cements (cements C, D and E) respectively. The powder-liquid type cements revealed significant correlation ( $r=0.861, p=0.0276$, Fig. 6 (b)) between the retentive forces and shear strengths but the paste-mixing type cements did not $(r=0.295, p=0.5700$, Fig. 7 (b)).

\section{DISCUSSION}

The present study found that the retentive force values of the crown to the abutment varied from $27 \mathrm{~N}$ to $109 \mathrm{~N}$ among the temporary cements examined at seven days and from $18 \mathrm{~N}$ to $80 \mathrm{~N}$ at 28 days. Although the cements examined in the study are all classified as "temporary" cements, the retention capacity is not the same among them, as reported by Sheets et $a l .{ }^{25)}$. The retentive strength of a crown to the abutment was reportedly higher ${ }^{9,25)}$ using the polycarboxylate temporary cements; in fact, this study also showed that one of polycarboxylate cements tested (hard-set type) had the highest retentive force. The zinc oxide eugenol cement (powder-liquid mixing type) tested in this study produced the lowest retentive force. In previous reports ${ }^{17,20)}$, reinforced zinc oxide eugenol cements were found to have greater retentive strength values. The measured retentive force

Table 5 Summary of analysis of variance for retentive force

\begin{tabular}{lcrrrr}
\hline \multicolumn{1}{c}{ Source } & Type III Sum of squares & df & Mean Square & F & Sig. \\
\hline Corrected Model & $90997.313^{\mathrm{a}}$ & 11 & 8272.483 & 21.274 & .000 \\
Intercept & 495499.864 & 1 & 495499.864 & 1274.261 & .000 \\
Time & 6844.680 & 1 & 6844.680 & 17.602 & .000 \\
Cement & 79711.985 & 5 & 15942.397 & 40.999 & .000 \\
Time×Cement & 4440.649 & 5 & 888.130 & 2.284 & .051 \\
Error & 41996.104 & 108 & 388.853 & - & - \\
Total & 628493.281 & 120 & & - & - \\
Corrected Total & 132993.417 & 119 & - & - \\
\hline
\end{tabular}

a: R Squared=.684 (Adjusted R Squared=.652) 

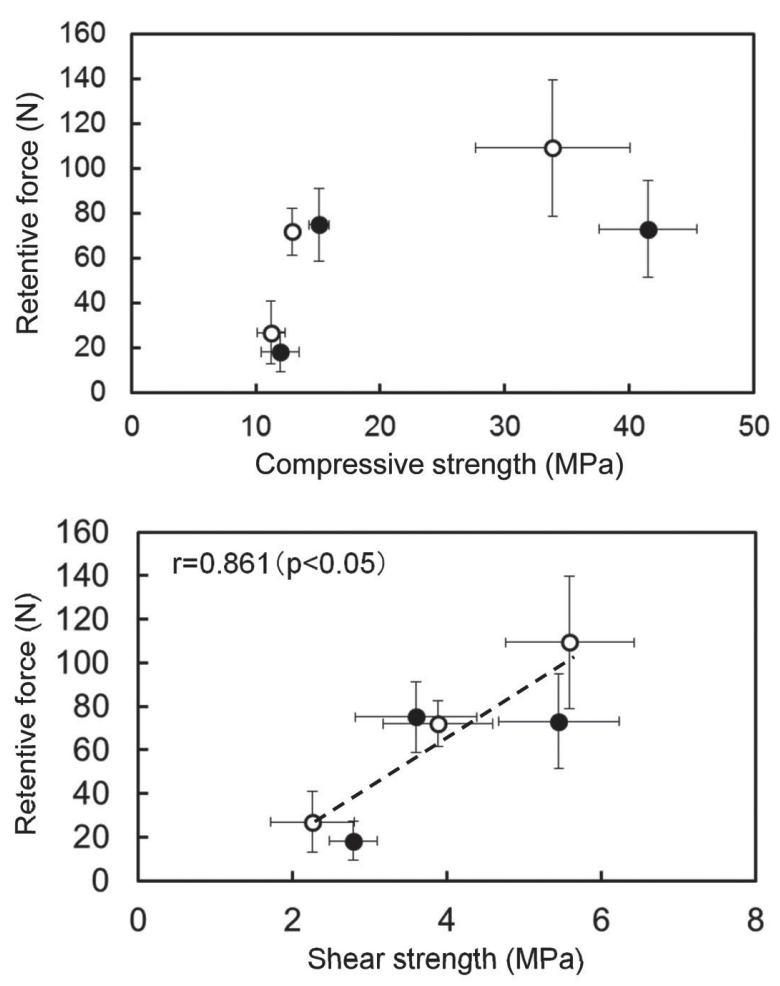

Fig. 6 Relationships between mechanical strengths and retentive force values of powder-liquid type temporary cements used in this study.

Bars with symbol indicate one standard deviation. Open and solid circles represent 7-day and 28-day values, respectively (a) Relationships between compressive strength and retentive force values. (b) Relationships between shear strength and retentive force values.

of the zinc oxide eugenol cement in the present study was low because it was not the reinforced type. Regardless of the eugenol content, the paste-mixing type cements had intermediate retentive forces after seven days; however, the paste-mixing type cements with eugenol displayed a significant reduction in retentive force after 28 days.

The previous studies $^{8-11,19,20)}$ investigating the retentive forces of cements showed a wide range of retentive force values ( $16 \mathrm{~N}$ to $467 \mathrm{~N}$ ). This discrepancy was attributed to differences in the experimental conditions in the tests. Of the various experimental conditions in the previous studies, the geometry of the abutments such as the taper, diameter, height and abutment design may be the dominant factors affecting the determination of the retentive force of the crown to the abutment.

The clinically optimum retentive force of the crown to the cement-retained implant abutment could not be determined from the present study. In many clinical cases, the use of temporary cements for cement-retained implants has been adopted ${ }^{9,11,15)}$. Therefore, the data obtained from this study are expected to fall within the

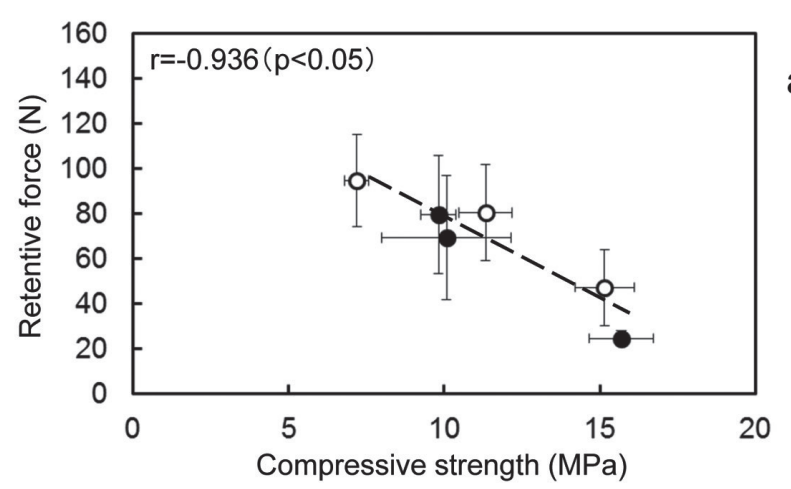

a

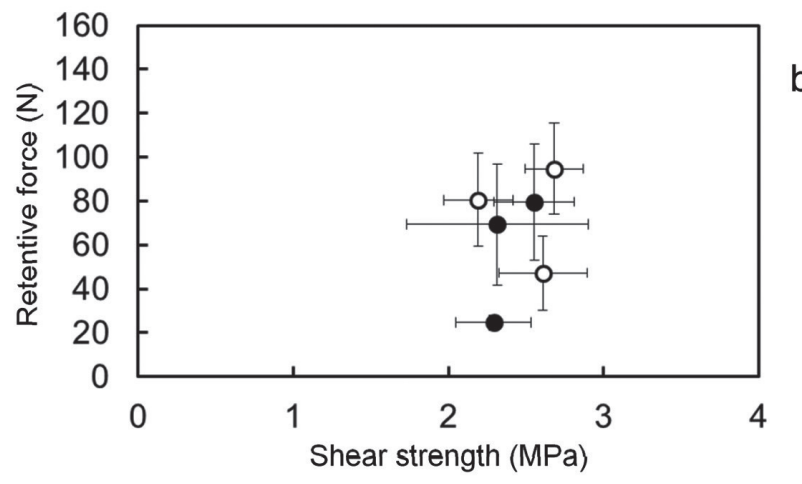

Fig. 7 Relationships between mechanical strengths and retentive force values of paste-mixing type temporary cements used in this study.

Bars with symbol indicate one standard deviation. Open and solid circles represent 7-day and 28-day values, respectively (a) Relationships between compressive strength and retentive force values. (b) Relationships between shear strength and retentive force values.

acceptable range of retentive force.

Because temporary cements do not need to have a strong chemical affinity to adhere to the substrate surface, the crowns are retained by the temporary cements mainly through a mechanical interlocking mechanism. The observation of cement failure in the present study indicated that seven days after the start of storage, a residual cement mass remained on the inner surface of the crown (Table 2). This residual mass showed that the failure occurred mainly at the interface between the cement layer and the abutment surface during retentive force testing. Since the inner surface of the crown was finished by alumina particle abrasion, the crown surface was rougher compared to the abutment surfaces, which were finished by machining. Thus, the measured retentive force depended upon the adhesive nature of the cement on the titanium abutment surface.

The retentive force, particularly for cements B and E, was reduced after 28 days, possibly because the breakdown of the adhesion between the cement layer and the inner surface of the crown was initiated due to moist storage conditions. 
The zinc oxide eugenol cement $\mathrm{F}$ decreased in retentive force with time but the failure mode was not altered. Kan et $a l .{ }^{26)}$ reported that the retentive force of a zinc oxide eugenol temporary cement on a metal crown was reduced by approximately $50 \%$ from one week to one month of immersion in water. Our study corroborated the findings in a previous study regarding the trend in changes in retentive force for zinc oxide eugenol cement. Since the cement always failed at the interface between the cement layer and the abutment surface (even after 28 days), moisture during storage might have a more deleterious effect on the adhesiveness of the cement, particularly to titanium abutment surfaces. Further investigation is required to examine the reduction in retention of metal crowns using temporary zinc oxide eugenol cement.

In general, the mechanical properties of these cements affect the retention of the prosthesis to the abutment ${ }^{23,27-29)}$ but there are few reports on the mechanical properties of temporary cements ${ }^{21.22,29-31)}$. Lee et $a l .{ }^{19)}$ reported that an increase in the compressive strength of the cement increased the retentive force of the crown when tested with a paste-mixing type temporary cement with eugenol (Temp Bond). Their study examined single temporary cement that had different compressive strengths obtained by various mixing conditions.

Tables 3 and 4 list the compressive and shear strengths of commercial temporary cements that were the brands identical to those used in this study. The data in this table were obtained from the cements with different batch numbers; however, our pilot study found that mechanical strengths obtained from the cements used in this study had values similar to the data reported in the previous studies.

As shown in Fig. 5, no significant correlation was found between the compressive or the shear strength and the retentive force values when examined for all types of temporary cements. These results suggest that the retention of crown on abutment does not simply depend upon the compressive and shear strengths of temporary cements and the materials characteristics other than mechanical strengths would further contribute to retain the crowns. The present study then divided the temporary cements into two groups such as powder-liquid type and paste-mixing type, based on the dispensing type of cements. For the powder-liquid type cements, a significant correlation was found between the shear strength and the retentive force $(r=0.861, p<0.05$, Fig.6 (b)), but the compressive strength did not show a significant correlation to the retentive force $(r=0.634$, $p>0.05$ Fig.6 (a)). For the paste-mixing type cements, there was no significant correlation between the shear strength and the retentive force $(r=0.295, p>0.05$, Fig. 7 (b)). Meanwhile a negative correlation was found for the compressive strength to the retentive force $(r=-0.936$, $p<0.05$, Fig.7 (b)) of the paste-mixing cements. The present study suggests that the relationships between the mechanical strength of cements and the retentive force to the implant abutment exhibit an inconsistent trend if the types of mechanical strengths and cement dispensing vary.

The compressive strength is known to be very useful mechanical property for comparing materials that are brittle and generally weak in tension such as dental cements, but it is difficult to determine the compressive properties of ductile materials ${ }^{32)}$. The compressive strength test is considered not to be most appropriate method to examine all temporary cements because some temporary cements, such as paste-mixing type cements which contain some mineral oils, wax and petrolatum, show ductile behavior during testing as compared to deformation behavior of ordinary luting cements. Failure of test specimen by compression loading is known to occur as a result of complex stress (compressive, tensile and shear stresses) yielded within the specimen body ${ }^{32}$. This stress condition may make temporary cements with low strength and ductile nature more difficult to determine their true compressive strength. A trend was reported that the greater mechanical (compressive) strength of luting cements provides the greater bond strength to the substrate material ${ }^{23)}$. In the present study, we could not provide clear explanation for the reasons why a negative correlation between compressive strength and retentive force was found for the pastemixing cement. The purpose of use and the retention mechanism in temporary cements are different from the luting cements. The retentive force of temporary cements may be influenced by viscosity, stickiness, wettability and/or mechanical interlocking force of the cements, in addition to mechanical strengths of cement layer. Further investigation must be needed to clarify the relationships between the compressive strength and the retentive force of temporary cements.

The shear strengths of temporary cements were taken into consideration in this study because the cement layer on axial wall of abutment is subjected to shear stress when the crown is removed from the abutment. Shear strength reported in our previous study were determined by shear punch-out method which punched out rounded thin $(1 \mathrm{~mm})$ specimen, and this method is believed to provide the intrinsic strength of thinner materials.

This study implies that the greater shear strength led the greater retentive force for the powder-liquid type temporary cement because of greater shear resistance to fail the cement layer and/or the cement interfaces to substrates; however, it was not true for the paste-mixing type temporary cements. The present study suggests general trend of the relationships between shear strength and retentive force among various temporary cements. Apart from cement B, the other temporary cements with weaker mechanical strength did not always have less retentive force to the crown as seen in paste-mixing type cements. The retention to the crown may be affected by shear strength of powder-liquid type cements as reported in this study and by factors other than mechanical strength, e.g., the characteristics of the cement film, stickiness of the cement mass, fluidity of the cement mix when the crown is seated, etc. In summary, the present study suggested that the mechanical 
strength of commercially available temporary cements could not be a prominent predicting factor to retain the crowns to the implant abutments. Further investigation is needed to identify the factors affecting the retention mechanism to the crown by the cement and the physical and mechanical properties of the temporary cements.

From the results of this study, the present study accepted the hypothesis that the retentive force of crown to implant abutment by temporary cements depend on the types of cements and the time after seating for some cements. However, another hypothesis that the retentive forces of the crown to the implant abutment correlate with mechanicals strengths of the cements could not be fully accepted because the correlations were found depending upon the types of mechanical strength and the types of cement dispensing.

\section{CONCLUSIONS}

Within the limitations of this study, the following conclusions are drawn:

1. The retentive force of the commercially available temporary cements to implant abutments varied widely among the products;

2. The retentive force of all the temporary cements was not reduced as the time elapsed, except for two products tested;

3. Temporary polycarboxylate cements and pastemixing type eugenol free temporary cements reveal comparable retentive force after 28 days of storage; and,

4. The powder-liquid type cements showed significant correlation between the retentive force and the shear strength. While a negative correlation were obtained for paste-mixing type cement between the retentive force and compressive strength. Mechanical strength of temporary cements could not be a prominent predicting factor for retention of the crowns on the abutments.

\section{ACKNOWLEDGMENTS}

The study was supported by Grant-in-Aid for Young Scientists (B) 25861864 and by JSPS Grant-in-Aid for Scientific Research (C) 20592308. We would like to thank Mrs. Jeanne Santa Cruz for her editorial assistance with the manuscript preparation.

\section{REFERENCES}

1) Walton JN, Gardner FM, Agar JR. A survey of crown and fixed partial dentures: length of service and reasons for replacement. J Prosthet Dent 1986; 56: 416-421.

2) Schwarts NL, Whitsett LD,Berry TD, Stewart JL. Unserviceable crowns and fixed partial dentures: life span and causes for loss of serviceability. J Am Dent Assoc 1970; 81: 1395-1401.

3) Libby G, Arcuri MR, Lavelle WE, Hebl L. Longevity of fixed partial dentures. J Prosthet Dent 1997; 78:127-131.

4) Adell R, Erikson B, Lelholm U, Brånemark P-I, Jemt T.
Long term follow-up study of osseointegrated implants in the treatment of totally edentulous jaws. Int J Oral Maxillofac Implants 1990; 8: 357-359.

5) Attard NJ, Zarb GA. Implant prosthodontic management of partially edentulous patients missing posterior teeth: The Toronto experience. J Prosthet Dent 2003; 89: 352-359.

6) Keith SE, Miller BH, Woody RD, Higginbottom FL. Marginal discrepancy of screw-retained and cemented metal-ceramic crowns on implant abutment. Int J Oral Maxillofac Implants 1999; 14: 369-378.

7) Hebel KS, Gajjar RC. Cement-retained versus screw-retained implant restorations: Achieving optimal occlusion and esthetics in implant dentistry. J Prosthet Dent 1997; 77: 2835 .

8) Michalakis KX, Pissiotis AL, Hirayama H. Cement failure loads of 4 provisional luting agents used for the cementation of implant-supported fixed partial dentures. Int $\mathrm{J}$ Oral Maxillofac Implants 2000; 15: 545-549.

9) Akça K, Iplikçioğlu H, Çehreli MC. Comparison of uniaxial resistance forces of cements used with implant-supported crowns. Int J Oral Maxillofac Implants 2002; 17: 536-542.

10) Bernal G, Okamura M, Muñoz CA. The effects of abutment taper, length and cement type on resistance to dislodgement of cement-retained, implant-supported restorations. J Prosthodont 2003; 12: 111-115.

11) Wolfart M, Wolfart S, Kern M. Retention forces and seating discrepancies of implant-retained castings after cementation. Int J Oral Maxillofac Implants 2006; 21: 519-525.

12) Torrado E, Ercoli C, Mardini MA, Graser GN, Tallents RH, Cordaro L. A comparison of the porcelain fracture resistance of screw-retained and cement-retained implant-supported metal-ceramic crowns. J Prosthet Dent 2004; 91: 532-537.

13) Misch CE. In: Misch CE, editor. Dental Implant Prosthetics. 1st ed. St.Louis: Elsevier Mosby Co; 2005. p.414-451.

14) Piattelli A, Scarano A, Paolantonio M, Assenza B, Leghissa GC, Bonaventura GD, Catamo G, Piccolomini R. Fluids and microbial penetration in the internal part of cement-retained versus screw-retained implant-abutment connections. J Periodontol 2001; 72: 1146-1150.

15) Squire RS, Agar JR, Duncan JP, Taylor TD. Retentiveness of dental cements used with metallic implant components. Int $J$ Oral Maxillofac Implants 2001; 16: 793-798.

16) Ramp MH, Dixon DL, Ramp LC, Breeding LC, Barber LL. Tensile bond strength of provisional luting agents used with an implant system. J Prosthet Dent 1999; 81: 510-514.

17) Millstein PL, Hazan E, Nathanson D. Effect of aging on temporary cement retention in vitro. J Prosthet Dent 1991; 65: 768-771.

18) Kaar D, Oshida Y, Andres CJ, Barco T, Platt JA. The effect of fatigue damage on the force required to remove a restoration in a cement-retained implant system. J Prosthodont 2006; 15: 289-294.

19) Lee SY, Wang CC, Chen DC, Lai YL. Retentive and compressive strengths of modified zinc oxide-eugenol cements. J Dent 2000; 28: 69-75.

20) Olin PS, Rudney JD, Hill EME. Retentive strength of six temporary dental cements. Quintessence Int 1990; 21: $197-$ 200.

21) Nagasawa Y, Hibino Y, Yamazaki A, Honda M, Omatsu J, Hasegawa Y, Harashima A, Nakajima H. Changes in shear strength of temporary cements with time. J J Dent Mater 2006; 25: 290-295.

22) Nagasawa Y, Hibino Y, Harashima A, Yamazaki A, Honda M, Omatsu J, Hasegawa Y, Kuramochi K, Yamaga T, Nakajima $\mathrm{H}$. Effect of ambient water on strength of temporary cements. J J Dent Mater 2006; 25: 33-40.

23) Hibino Y, Kuramochi K, Hoshino T, Moriyama A, Watanabe $\mathrm{Y}$, Nakajima $\mathrm{H}$. Relationship between the strength of glass ionomers and their adhesive strength to metals. Dent Mater 
2002; 18: 552-557.

24) American Society for Testing and Materials Standards. Standard test method for shear strength of plastics by punch tool, ASTM. D732:1990.

25) Sheets JL, Wilcox C, Wilwerding T. Cement selection for cement-retained crown technique with dental implants. J Prosthodont 2008; 17: 92-96.

26) Kan S, Aoyama S, Shimizu T, Inami T, Hanamura N. Retention of zinc oxide-eugenol cement for temporary cementation. J Jpn Prosthodont Soc 1982; 26: 1021-1027.

27) Hibino Y, Kuroiwa A, Kurosawa S, Kanke S, Hashimoto H. Bond strength of dental luting cements to titanium castings. J J Dent Mater 1990; 9: 79-85.

28) Browning WD, Nelson SK, Cibirka R, Myers ML. Comparison of luting cements for minimally retentive crown preparations. Quintessence Int 2002; 33: 95-100.

29) Swartz ML, Phillips WR, Norman RD, Oldham DF. Strength, hardness and abrasion characteristics of dental cements. J Am Dent Assoc 1963; 67: 367-374.

30) Mesu FP. The effect of temperature on the compressive and tensile strengths of cements. J Prosthet Dent 1983; 49: 5962 .

31) Lawson NC, Burgess JO, Mercante D. Crown retention and flexural strength of eight provisional cements J Prosthet Dent 2007; 98: 455-460.

32) Kohn DH. In: Craig RG and Powers JM, editor. Restorative dental materials. 11th ed. St. Louis: Mosby Inc.; 2002. p.8485 . 